\title{
Pseudohypoparathyroidism type 2
}

INSERM

\section{Source}

INSERM. (1999). Orphanet: an online rare disease and orphan drug data base.

Pseudohypoparathyroidism type 2. ORPHA:94090

Pseudohypoparathyroidism type 2 (PHP2) is a type of pseudohypoparathyroidism (PHP; see this term) characterized by resistance to parathyroid hormone (PTH), which manifests with hypocalcemia, hyperphosphatemia and elevated PTH levels, absence of Albright's hereditary osteodystrophy (AHO; see this term), and normal expression of the Gs protein with a normal urinary cAMP response. 